\title{
Influence of Ageing on Flexible Pavement Interface Bond under Repeated Shear Stresses
}

\author{
Saad Issa Sarsam ${ }^{1}$, Samah Abdulrazzaq AL Nuaimi ${ }^{2}$ \\ 1,2Department of Civil Engineering, College of Engineering, University of Baghdad, Iraq \\ Email: saadisasarsam@coeng.uobaghdad.edu.iq
}

\begin{abstract}
:
The durability of interface bond was not sufficiently taken into consideration, and the research work in this field is scares and scattered. The interface bond usually practices dynamic shear stresses throughout its service life while ageing due to volatilization provide stiffness at the interface. In this investigation, an attempt has been made to assess the durability of the interface bond in terms of resistance to ageing under repeated shear stresses. Two types of tack coat (Rapid Curing cutback RC-70 and Cationic Medium setting emulsion CMS) and three application rates have been implemented in the preparation of two layers slab samples (base overlaid by binder, and binder overlaid by wearing) courses using roller compactor. Asphalt concrete core specimens were obtained from the roller compacted slab samples and subjected to long term ageing, then the specimens were subjected to 1200 repeated shear stress cycles. The accumulation of permanent deformation was monitored. Afterwards, the specimens were tested for interface shear strength at $20^{\circ} \mathrm{C}$. Control specimens were also tested for comparison. It was concluded that ageing reduces the total microstrain for RC-70 tack coat by (43.6, 25.6, and $29.5) \%$ and $(50,51.3$, and 30.2) \% for (binder-base) and (wearing-binder) interfaces for the application rate of $(0.15,0.33,0.5) \mathrm{l} / \mathrm{m} 2$ respectively. However, ageing reduces the total microstrain for CMS tack coat by $(37,35.5$, and 40.3) \% and $(45.2,49$, and 46.8) \% for (binder-base) and (wearing-binder) interfaces for the application rate of $(0.1,0.23,0.35) \mathrm{l} / \mathrm{m} 2$ respectively. Ageing increases the interface bond shear strength by a range of (8-27)\% for various interfaces, tack coat type and application rates.
\end{abstract}

Keywords:

asphalt concrete; durability; ageing; repeated shear stress; interface bond; tack coat

\section{Introduction}

In general, tack coats are not sufficiently taken into consideration in most pavement design procedures, while acceptable bonding at interface is not always achieved. Thus, shear distress becomes excessive at particular spots of the road, slippage failure between layers appears which reduces the service life of the pavement. This process can occur in horizontal curves, intersections, and zones with ascending or descending gradients, causing surface distress, (Muslich, 2010). The influence of ageing on the interface bonding properties of two layered asphalt concrete was evaluated by (Raab et al., 2016). The evaluation discusses the behavior of specimens obtained from laboratory and in situ pavements. The findings demonstrate that ageing has a positive effect on the interface bond of asphalt pavements and that long-term oven ageing can lead to similar results as that of in situ ageing. It was concluded that a maximum strength of interface may roughly increase by $1 \%$ per month over a period of 10 years. Karakas, 2018 focuses on Asphalt concrete ageing process during construction, transportation, application phases and service life, as well. It was stated that exposure to environmental conditions such as traffic and climate is one of the prominent reasons of ageing in asphalt concrete. The most common mechanism of ageing is the degradation in the chemical structure of the binder by oxidation. It was concluded that asphalt concrete ageing could cause several serious distresses on the pavement such as stiffening, 
stripping that accelerates fatigue cracking, raveling and potholes. Swarna, 2018 stated that when there is an increase in interface bond strength, the strains at the bottom of the asphalt concrete overlay are reduced, which corresponds to the high fatigue life of the pavement. An overlay without any interface bonding will lead to the premature cracking of pavement. The typical distress caused by the inadequate bond between an asphalt concrete wearing course and the beneath layer is slippage cracking. This occurs most often in areas where braking or turning wheels cause the pavement surface to slide or deform (at intersections, sharp curves) and can occur under a simple rolling wheel load. Shahin et al., 1986 describes the slippage cracks as crescent or half-moon-shaped cracks having two ends pointed away from the direction of traffic as demonstrated in Figure 1.
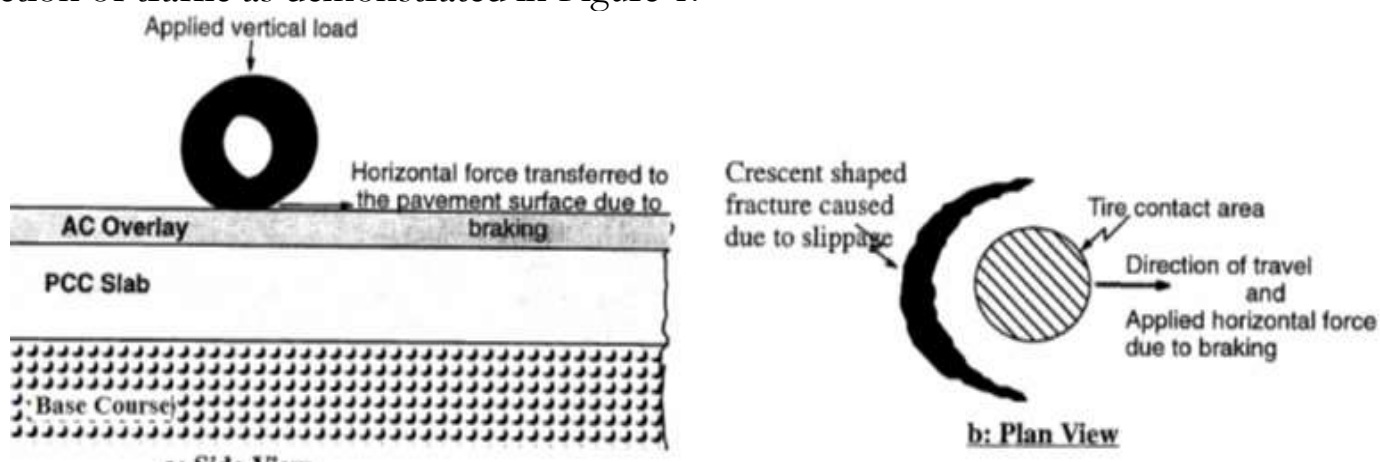

Figure 1. Slippage Cracks Due to Inadequate Bond at Interface (Shahin et al., 1986)

The redistribution of stresses and strains in the pavement structure due to inadequate interface bond condition has been considered as a cause of distress for road structures. The principal types of distress, such as slippage, delamination, and top-down cracking are due to the tack coat quality and its capacity to bond two layers. When the adhesion between pavement layers is low, the asphalt binder tends to crack early with increases rutting due to the internal energy consumption of the material, resulting in fatigue problems and top-down cracks (Raab and Partl, 2009). Lack of interface proper bonding can lead to several premature distresses such as slippage cracking, delamination and distortion of the pavement. Slippage cracks usually formed in the surface course, are generally formed in the opposite direction of horizontal force on the pavement. However, delamination involves loss of bond between various lifts of asphalt concrete while distortion is the deformation occurring predominantly mainly in the surface course. (Kulkarni, 2004). Figure 2 demonstrates the delamination failure. Figure 3 shows the critical locations for shear and tensile stresses under truckloads (Raab and Partl 2004). It can be observed that shear stresses created under the truck tire induces tensile stresses in front of the tire. For this reason, laboratory and field experiments focus on both shear and tensile strength of the tack coats to evaluate the long-term resistance.

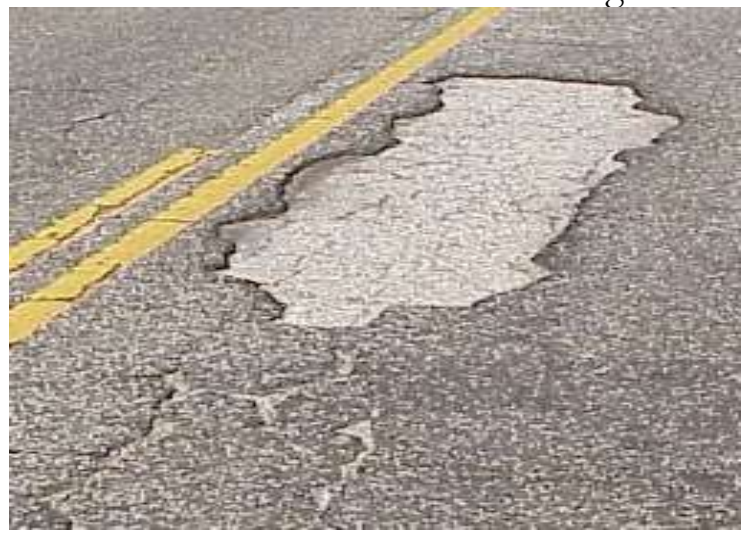

Figure 2. Delamination of Pavement (Kulkarni, 2004) 


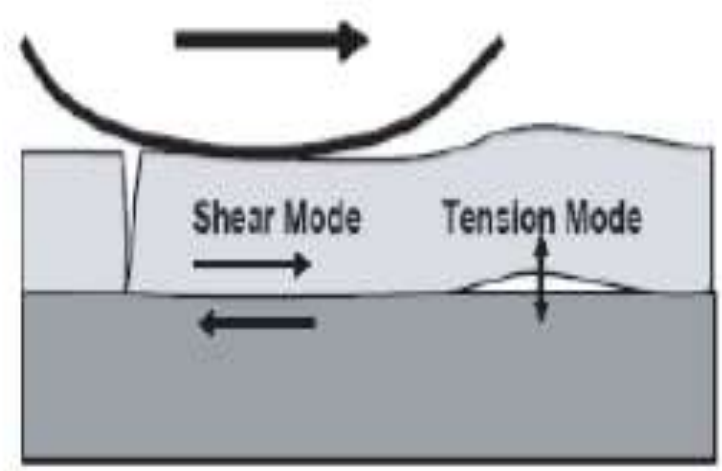

Figure 3. Distress Modes at Interface (Raab \&Part12004)

Flexible pavement analysis assumes that all bounded layers can work as one single layer, this is seriously misleading if the bond at one or more-layer interfaces is weak or has failed. The fatigue property of a pavement layer above an interface is very sensitive to variations in layer dynamic stiffness modulus, environmental conditions, layer thickness and the degree of lateral movement available at the interface. (Khweir, and Fordyce, 2003). Generally, the sustainability issue of pavement materials is considered globally to reserve the resources and reduce the impact on the environment, Nurmaidah and Pradana, (2019).

The aim of the present investigation is to assess the durability of interfaces bond of flexible pavement layers in terms of resistance to long term aging under the action of repeated shear stresses. Two types of tack coat and three types of application rates will be implemented.

\section{Review of Literatures}

\subsection{Asphalt Cement}

The asphalt cement used in this investigation is obtained from Dura refinery, south of Baghdad. Penetration graded binder of 40-50 is used. The physical properties of the binder are presented in Table 1.

Table 1. Physical Properties of Asphalt Cement

\begin{tabular}{|c|c|c|c|c|c|}
\hline Test & Test condition & $\begin{array}{l}\text { ASTM,2013 } \\
\text { Designation }\end{array}$ & Units & $\begin{array}{l}\text { SCRB, } 2003 \\
\text { Specification }\end{array}$ & $\begin{array}{l}\text { Test } \\
\text { result }\end{array}$ \\
\hline Penetration & $\begin{array}{l}100 \mathrm{gm}, 25 \mathrm{C}^{\circ}, 5 \mathrm{sec} \\
(1 / 10 \mathrm{~mm})\end{array}$ & D-5 & $1 / 10 \mathrm{~mm}$ & $40-50$ & 46.5 \\
\hline Specific Gravity & @ $25^{\circ} \mathrm{C}$ & D-70 & $\mathrm{gm} / \mathrm{cm}^{3}$ & ------- & 1.05 \\
\hline Flash point & ${ }_{\text {cup }}$ Cleveland open & D-92 & ${ }^{\circ} \mathrm{C}$ & $>232$ & 285 \\
\hline Ductility & $25^{\circ} \mathbf{C}, 5 \mathrm{~cm} / \mathrm{min}$ & D-113 & $\mathrm{cm}$ & $>100$ & $>150$ \\
\hline Softening point & Ring and ball & D-36 & ${ }^{\circ} \mathrm{C}$ & ------- & 48 \\
\hline $\begin{array}{l}\text { Kinematic } \\
\text { viscosity }\end{array}$ & @ $135^{\circ} \mathbf{C}$ & D2170 & C. Stoke & ------- & 230 \\
\hline \multicolumn{6}{|c|}{ Residue after thin film oven test } \\
\hline $\begin{array}{l}\text { Penetration of } \\
\text { residue }\end{array}$ & $\begin{array}{l}\text { 100gm, 25C , 5 sec } \\
(1 / 10 \mathrm{~mm})\end{array}$ & D 5 & $1 / 10 \mathrm{~mm}$ & $40-50$ & 36.5 \\
\hline $\begin{array}{l}\text { Ductility of } \\
\text { residue }\end{array}$ & $25^{\circ} \mathbf{C}, 5 \mathrm{~cm} / \mathrm{min}$ & D113 & $\mathrm{cm}$ & $>55$ & 145 \\
\hline Loss in weight & 5 hours at $163 \mathrm{C}^{\circ}, 50 \mathrm{gm}$ & D 1754 & $\%$ & $<0.75$ & 0.13 \\
\hline
\end{tabular}




\subsection{Cut Back Asphalt}

Rapid curing Cut back RC-70 is implemented as tack coat which is widely used in Iraq. Such cut back is prepared by mixing one gasoline ratio into two ratios of asphalt cement (85-100) measured in volume. The physical properties of the RC-70 are presented in Table 2. Three application rates of $(0.15,0.33,0.5)$ liter $/ \mathrm{m}^{2}$ have been implemented which are within the limitations of state commission for roads and bridges (SCRB, 2003).

Table 2. Physical Properties of RC-70 Cut Back

\begin{tabular}{|l|l|c|c|c|}
\hline \multirow{2}{*}{ Test } & \multirow{2}{*}{$\begin{array}{c}\text { ASTM, 2013 } \\
\text { Designation }\end{array}$} & \multirow{2}{*}{$\begin{array}{c}\text { Cut Back } \\
\text { Asphalt }\end{array}$} & \multicolumn{2}{|c|}{$\begin{array}{c}\text { Specification Limits } \\
\text { ASTM, 2013 }\end{array}$} \\
\cline { 4 - 5 } & & & Minimum & Maximum \\
\hline Density (gm/liter) & D2028, D3142 & 995 & --- & --- \\
\hline Water concentration (\%) & D95 & $0.1 \%$ & --- & $0.2 \%$ \\
\hline Residual by Evaporation( \%) & D2028 & $90 \%$ & $55 \%$ & --- \\
\hline Kinematic viscosity (C. Stoke) & D2170 & 75 & 70 & 95 \\
\hline
\end{tabular}

\subsection{Cationic Emulsion}

Medium setting cationic emulsion CMS has been implemented as tack coat. This classification is based on the rate of breaking of the emulsion; that is, the rate at which the dispersed asphalt particles can be made to recombine to form a continuous film of asphalt cement. The physical properties of emulsion are illustrated in Table 3. Three application rates of $(0.1,0.23,0.35)$ liter $/ \mathrm{m}^{2}$ have been implemented which are within the limitations of state commission for roads and bridges (SCRB, 2003).

Table 3. Physical Properties of Emulsion

\begin{tabular}{|l|c|c|c|}
\hline Property & $\begin{array}{c}\text { ASTM, 2013 } \\
\text { Designation }\end{array}$ & Test Result & Limits \\
\hline Emulsion type & D2397 & $\begin{array}{c}\text { Cationic } \\
\text { (CMS) }\end{array}$ & $\begin{array}{c}\text { Medium } \\
\text { setting }\end{array}$ \\
\hline Residue by evaporation \% & D6934 & 54 & Min 40 \\
\hline Specific gravity, gm/cm ${ }^{3}$ & D70 & 1.04 & ------ \\
\hline Penetration (mm) & D5 & 219 & $100-250$ \\
\hline Ductility(cm) & D113 & 46 & Min 40 \\
\hline $\begin{array}{l}\text { Viscosity, Saybolt-Furol viscometer @ } \\
50^{\circ} \mathrm{C}-\text { AASHTO, 2013 }\end{array}$ & $\begin{array}{c}\text { AASHTO } \\
\text { M208 }\end{array}$ & 348 & $110-990$ \\
\hline Solubility in Trichloroethylene (\%) & D2042 & 97.7 & Min 97.5 \\
\hline $\begin{array}{l}\text { Emulsified asphalt / job aggregate } \\
\text { coating practice }\end{array}$ & D244 & Fair & Good \\
\hline
\end{tabular}

\subsection{Coarse Aggregate}

The rounded coarse aggregates are used for base course layer while crushed aggregates are implemented for binder and wearing course layers. Aggregates are obtained from ALNibaee quarry. Coarse aggregates consist of hard, strong, and durable pieces, free of coherent coatings. The nominal maximum size of course aggregate range between $(25 \mathrm{~mm})$ and retained on sieve No. $4(4.75 \mathrm{~mm})$ according to SCRB R/9, 2003 specification. The physical properties of the coarse aggregate are shown in Table 4.

\subsection{Fine Aggregate}

Two types of fine aggregate are used in this study, crushed and river sand fine aggregate were obtained from AL-Nibaee quarry. The fine aggregate ranges between $4.75 \mathrm{~mm}$ (No.4) sieve and retained on $0.075 \mathrm{~mm}$ (No.200) sieve. It consists of durable, hard and dry, tough, 
rough - surfaced and angular grains free of clay, loam or other deleterious substance according to (SCRB, 2003) specifications. The physical properties of the fine aggregate are illustrated in Table 4.

Table 4. Physical Properties of Aggregates

\begin{tabular}{|l|c|c|c|}
\hline Property & $\begin{array}{c}\text { Coarse } \\
\text { Aggregate }\end{array}$ & $\begin{array}{c}\text { Fine } \\
\text { Aggregate }\end{array}$ & $\begin{array}{c}\text { SCRB, 2003 } \\
\text { Limitations }\end{array}$ \\
\hline Bulk Specific Gravity(ASTM C-127 and C128) & 2.61 & 2.632 & --------- \\
\hline $\begin{array}{l}\text { Apparent Specific Gravity (ASTM C127and } \\
\text { C128) }\end{array}$ & 2.657 & 2.693 & -------- \\
\hline $\begin{array}{l}\text { Percent Water Absorption (ASTM C-127 and } \\
\text { C128) }\end{array}$ & 0.443 & 0.526 & $5 \%$ Max. \\
\hline $\begin{array}{l}\text { Percent Wear (Loss Angeles Abrasion)(ASTM } \\
\text { C-131) }\end{array}$ & 18.6 & ------- & $35-45$ \\
\hline Percent Sand equivalent D2419 & -------- & 55 & 45 min \\
\hline Angularity for coarse aggregate ASTM D5821 & $96 \%$ & ------ & 90 min \\
\hline Percent flat and elongated particles D4791 & Flat & $3 \%$ & $<10 \%$ \\
\cline { 2 - 4 } & Elongation & $5 \%$ & $5-1$ \\
\hline
\end{tabular}

\subsection{Mineral Filler}

Ordinary Portland cement was used as mineral filler. It is thoroughly dry and free from lumps or aggregation of fine particles. The physical properties are shown in Table 5.

Table 5. Physical Properties of Portland cement Filler

\begin{tabular}{|l|c|}
\hline Property & Test Result \\
\hline$\%$ passing Sieve No.200 $(0.075 \mathrm{~mm})$ & 97 \\
\hline Specific Gravity, gm $/ \mathrm{cm}^{3}$ & 3.14 \\
\hline Specific Surface Area $\left(\mathrm{m}^{2} / \mathrm{kg}\right)$ & 310.5 \\
\hline
\end{tabular}

\subsection{Combined Gradation of Asphalt Concrete}

The coarse and fine Aggregates used in this study were sieved and recombined in the proper proportions to meet the Base, binder, and Surface course gradations requirements. Figure 4 exhibit the aggregate gradations used to prepare mixtures for wearing, binder and, base courses respectively as per (SCRB, 2003).

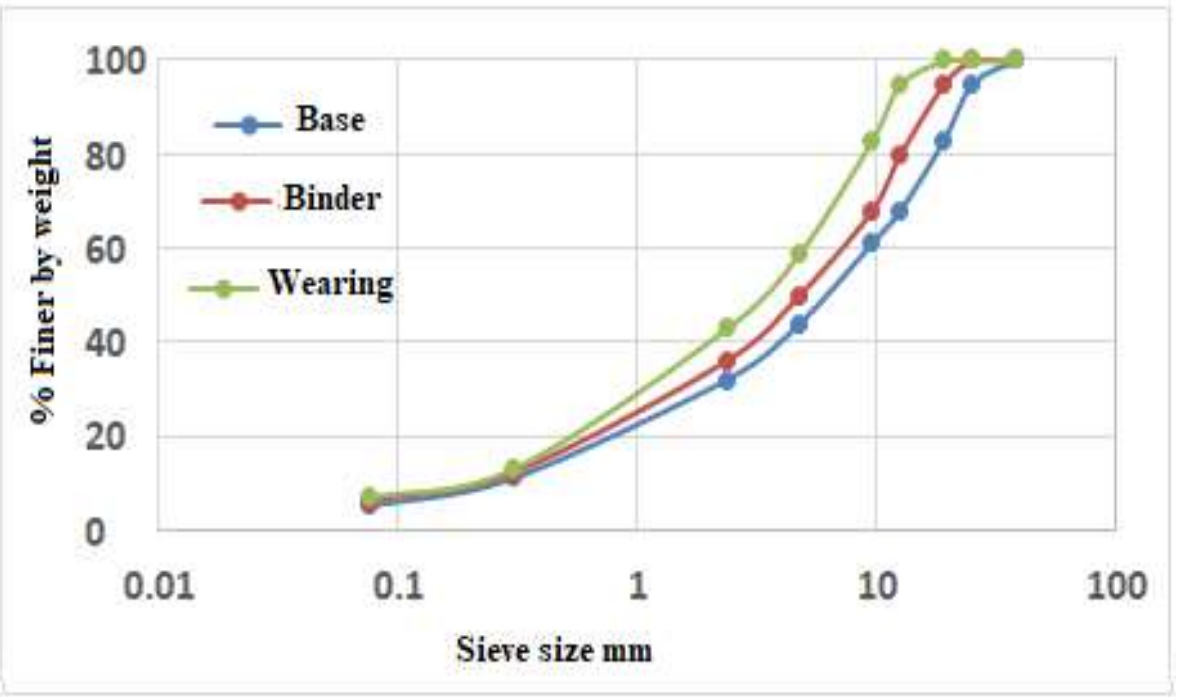

Figure 4. The Aggregate Gradation According to SCRB, 2003 


\section{Research Methods}

\subsection{Preparation of Asphalt Concrete Mixtures}

The aggregates were dried in an oven to a constant weight at $110{ }^{\circ} \mathrm{C}$, then sieved to different sizes, and stored separately. Coarse and fine aggregates were combined with mineral filler to meet the specified gradation of asphalt concrete layers as per (SCRB, 2003) specifications. The combined aggregate mixture was heated to $150^{\circ} \mathrm{C}$ before mixing with asphalt cement. The asphalt cement was heated to the same temperature of $150^{\circ} \mathrm{C}$, then it was added to the heated aggregate to achieve the desired amount and mixed thoroughly using mechanical mixer for two minutes until all aggregate particles were coated with thin film of asphalt cement. Marshall Size specimens were prepared in accordance with (ASTM D1559, 2013) using 75 blows of Marshall hammer on each face of the specimen for binder and wearing course mixtures. However, 50 blows of Marshall hammer on each face of the specimen for base course mixture was used. Specimens were tested for Marshall and volumetric properties, and the optimum asphalt content for each mixture was obtained.

\subsection{Preparation of Asphalt Concrete Slab Samples and Core Specimens}

Two types of asphalt concrete Slab specimens of $(400 \mathrm{~mm}$ by $300 \mathrm{~mm})$ were prepared using the roller compactor. The first type consists of base course of $80 \mathrm{~mm}$ thickness overlaid with binder course of $40 \mathrm{~mm}$. the second type consists of binder course of $60 \mathrm{~mm}$ overlaid with wearing course of $40 \mathrm{~mm}$. Pneumatic Roller Compactor B3602-DYNA, Ver 1.14, was implemented to prepare slab samples. Roller compaction was adopted as per (EN12697-33, 2007) with a static load start from $2.4 \mathrm{kN}$ for 10 cycles. The load was increased each 10 cycles to reach $9.1 \mathrm{kN}$ for a total of 33 cycles to meet the target density of the layer at optimum asphalt content. The compaction temperature was maintained to $135^{\circ} \mathrm{C}$. Figure 5 shows the roller compactor implemented. After the base course slab of the first type or the binder course of the second type were compacted, the slabs were left for 24 hours to cool at laboratory environment. Then the compacted slabs for each type were subjected to tack coat application at the specified application rate and tack coat type. Samples were left for 120 minutes to cure the tack coat, then overlaid by binder or wearing course mixtures and subjected to the roller compaction to the target density as explained above. Slab samples were left for 24 hours at the laboratory environment to cool. Slab samples were subjected to mean texture depth determination with the aid of sand patch method. Afterword, six Core specimens of $101 \mathrm{~mm}$ diameter were cut by the Diamond saw to the full depth of the slab which consists of two courses of asphalt concrete. The total number of slab samples prepared was 12 while, the total number of core specimens was 72. Figure 6 exhibits part of the prepared slab samples, while Figure 7 shows part of the obtained core specimens.

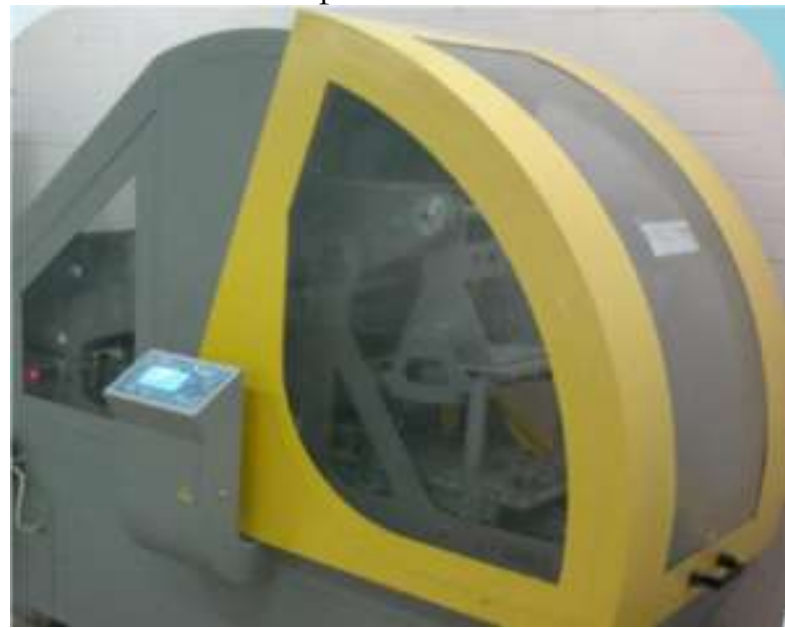

Figure 5. The Roller Compactor Implemented Samples 


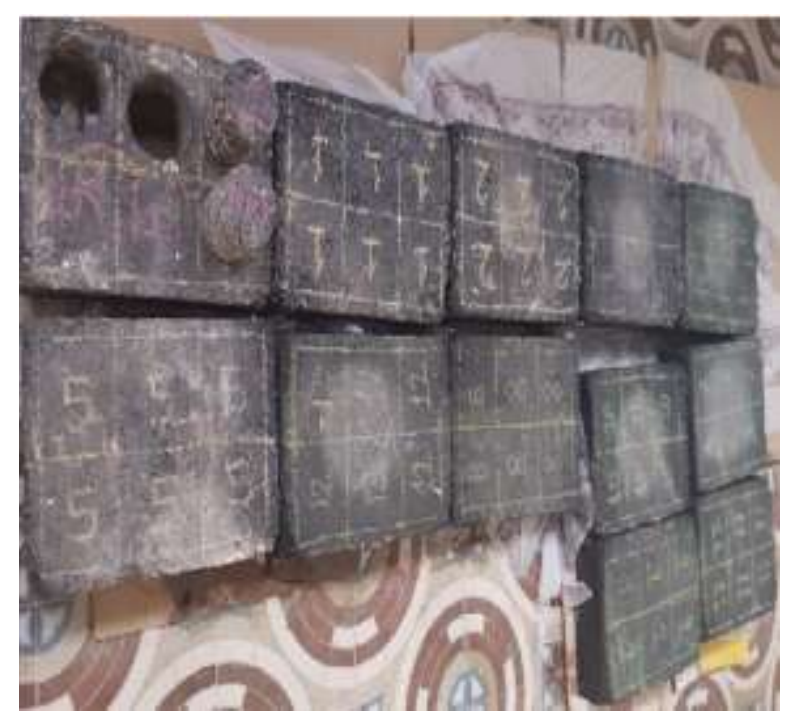

Figure 6. Part of the Prepared Slab

\subsection{Long-Term Ageing Process}

Part of the obtained core specimens were denoted as control specimens and were subjected to interface bond shear strength determination at $20^{\circ} \mathrm{C}$ under repeated loading. The second part of core specimens were subjected to long-term ageing process as per the procedure recommended by (AASHTO, 2013); (Raab et al., 2016) and (Karakas, 2018). Specimens were stored in an oven for five days as aging periods at $85^{\circ} \mathrm{C}$. specimens were withdrawn from the oven after the ageing period and conditioned in the laboratory at $20{ }^{\circ} \mathrm{C}$ overnight and denoted as aged specimens. Afterwards, the aged specimens were subjected to interface bond shear strength determination at $20^{\circ} \mathrm{C}$ under repeated loading. Figure 8 exhibit the long-term aging process.

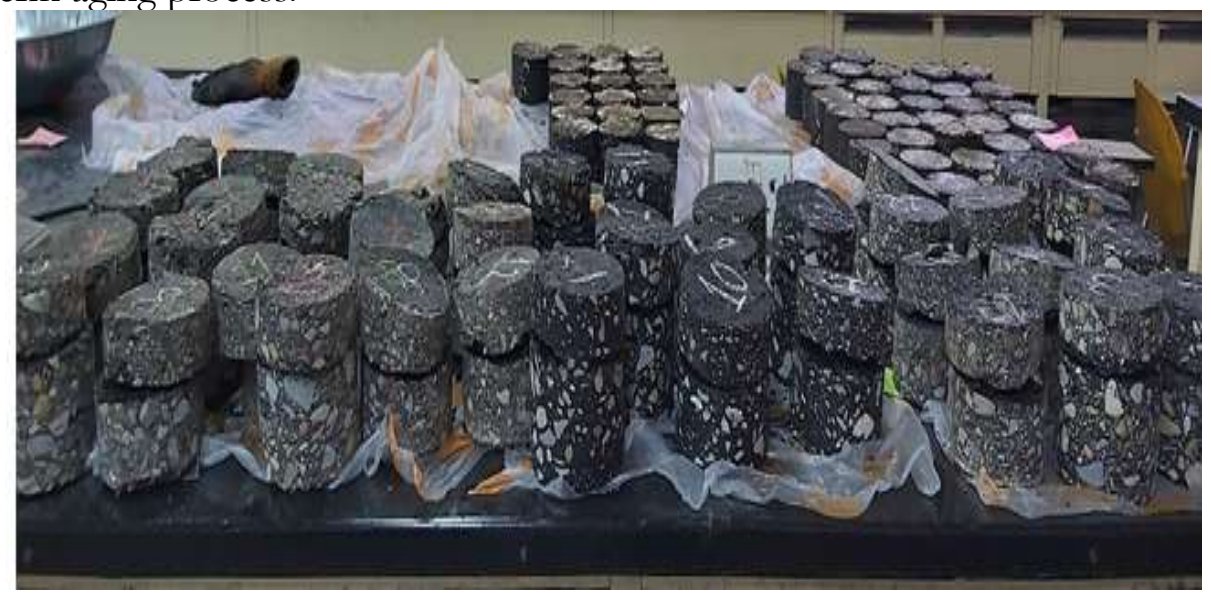

Figure 7. Part of the Obtained Core Specimens

\subsection{Interface Bond Shear Strength Test}

Shear test device consist of testing mold which was designed and manufactured at local market and implemented to evaluate interface shear strength. Figure 9 exhibit the testing mold. The test involves the application of a direct shear load and the resulting shear displacement during the test was monitored. The mold and the asphalt concrete specimen are placed in an environmental chamber capable of controlling the temperature to within 20 $\pm 0.5^{\circ} \mathrm{C}$. The test mechanism is such that one layer is held stationary in the mold while the other layer is loaded with a specific shear displacement rate. The specimens used in this study had a diameter of $110 \mathrm{~mm}$ and variable length of (100-120) $\mathrm{mm}$ based on testing combination of pavement layers. Specimens were subjected to repeated shear stress using the pneumatic 
repeated load system PRLS chamber shown in Figure 10 before testing the interface bond shear strength. The specimens were tested for bond shear strength. Testing was conducted at $20{ }^{\circ} \mathrm{C}$ at a constant loading rate of $5 \mathrm{~mm} / \mathrm{min}$. The interface bond shear strength is calculated by dividing the maximum load sustained by the specimen before failure by the cross-sectional area of the specimen. Similar testing mold and procedures were reported by (Mirsayar et al., 2017). (Raab et al., 2016); (Zhang, 2017); (Biglari et al., 2019).

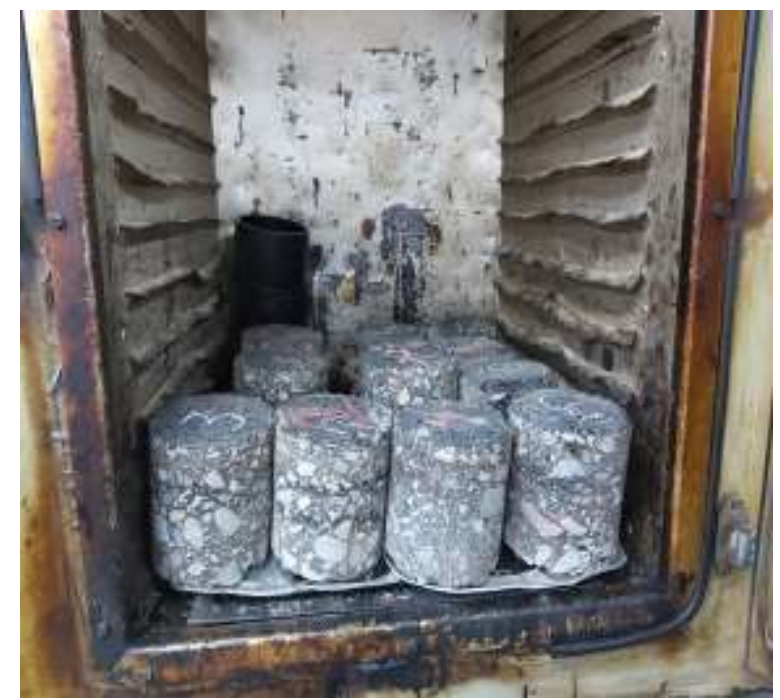

Figure 8. Long-term Ageing Process

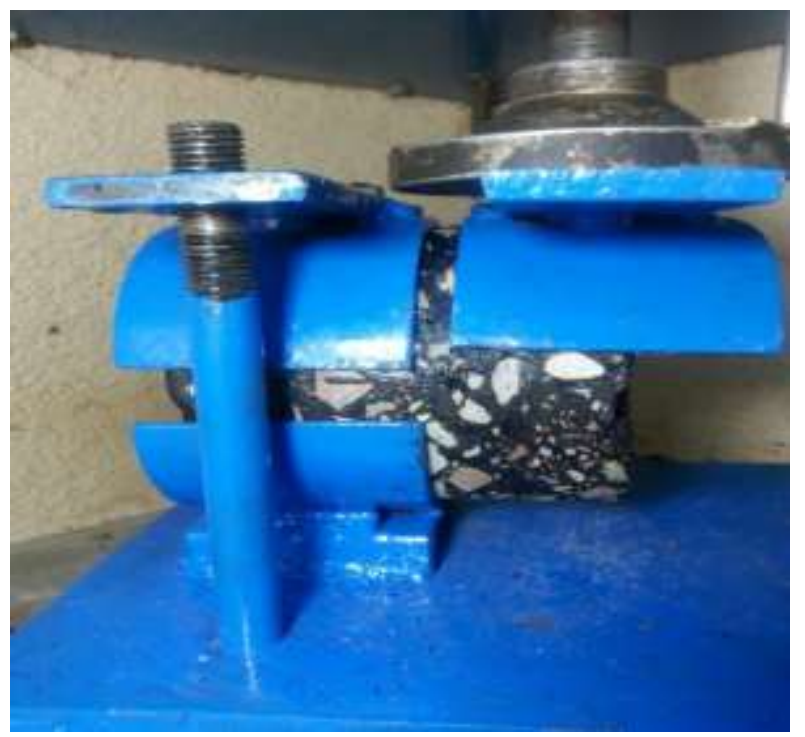

Figure 9. Interface Shear Testing Mold

\subsection{Repeated Bond Shear Strength Test}

The repeated shear stress test was conducted. The test was performed on core specimens, $110 \mathrm{~mm}$ in diameter and variable length. Cyclic shear loading was applied to the diametral specimen and the vertical strain is monitored under the load repetitions. Diametral loading is applied with a constant loading frequency of 60 cycles per minute and loading sequence for each cycle is 0.1 seconds of load duration and 0.9 seconds of rest period. Load repetitions was applied under constant stress level of $0.138 \mathrm{MPa}$, while the testing temperature of $20{ }^{\circ} \mathrm{C}$ was maintained throughout the test. Specimens were subjected to the application of repeated shear stresses for 1200 load repetitions. After 1200 load cycles, the test was terminated. The core specimens and the testing mold were transferred to the versa testing 
machine shown in Figure 11. Similar testing procedure was reported by (Sarsam and Hamdan, 2020).

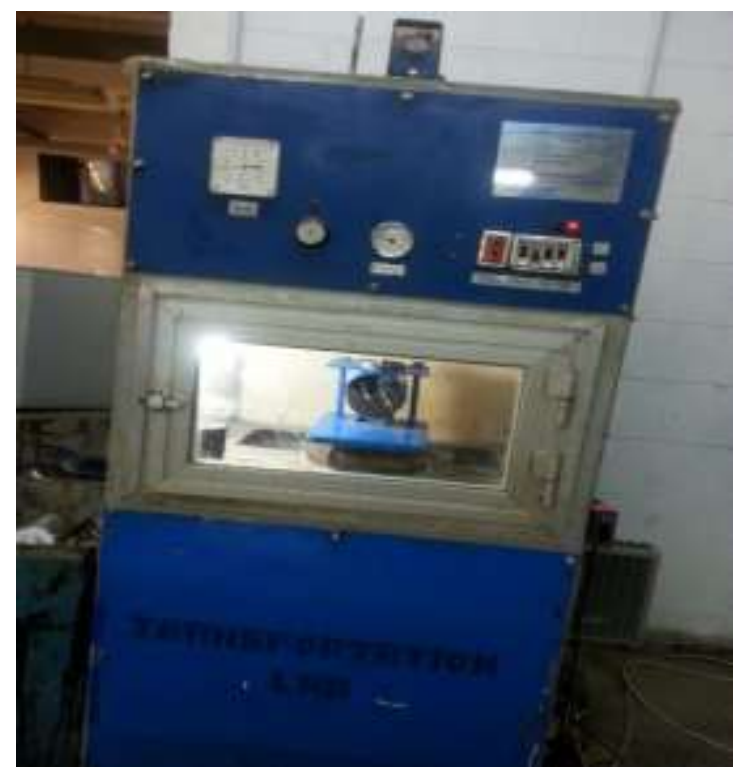

Figure 10. PRLS Testing Chamber

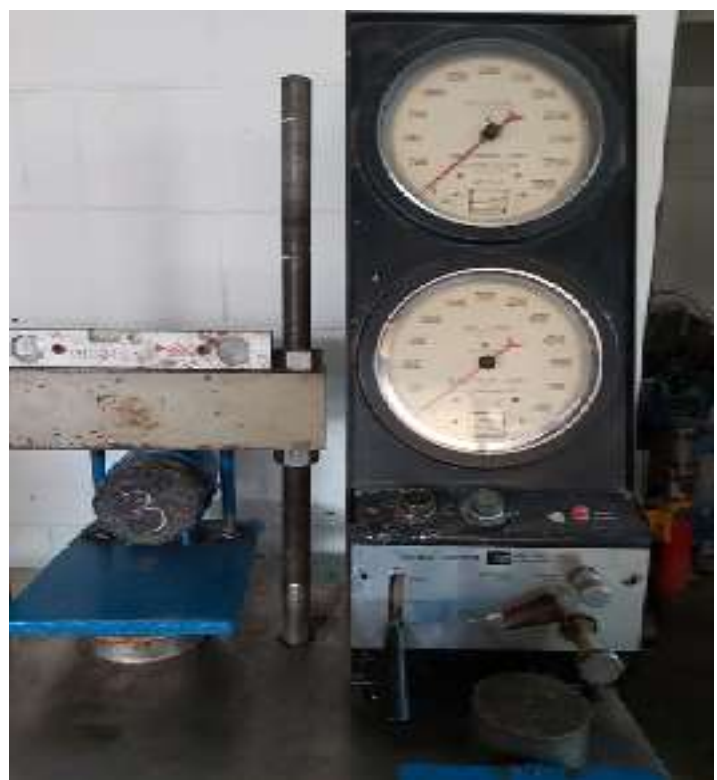

Figure 11. Versa Tester

\section{Discussion}

4.1 Impact of RC-70 Tack Coat and Ageing on Permanent Microstrain under Repeated Shear Stresses

Asphalt pavements are usually aged by oxidation of the asphalt and by evaporation of the lighter Maltenes from the asphalt cement, (Sarsam and Muayad, 2014). Figure 12 demonstrates the influence of repeated shear stresses and ageing process on permanent microstrain at the pavement interfaces when RC-70 tack coat was implemented. It can be noted that the impact of ageing on permanent microstrain is not significant for (binder-base) interface. 
This may be attributed to the coarse surface texture of base course which provide significant particle interlock between the layers at the interface in addition to the role of tack coat. The variation in the intercept which represent the permanent deformation after the first load repetition is minimal. On the other hand, the variation in the slope which represent the rate of deformation is not significant among various application rates of tack coat. The top and bottom layers show very similar trend lines of fatigue, suggesting that the fatigue activity of asphalt mixture for top and bottom layers is aged to the same degree after long-term aging process. Similar findings were reported by (Hu et al., 2016).

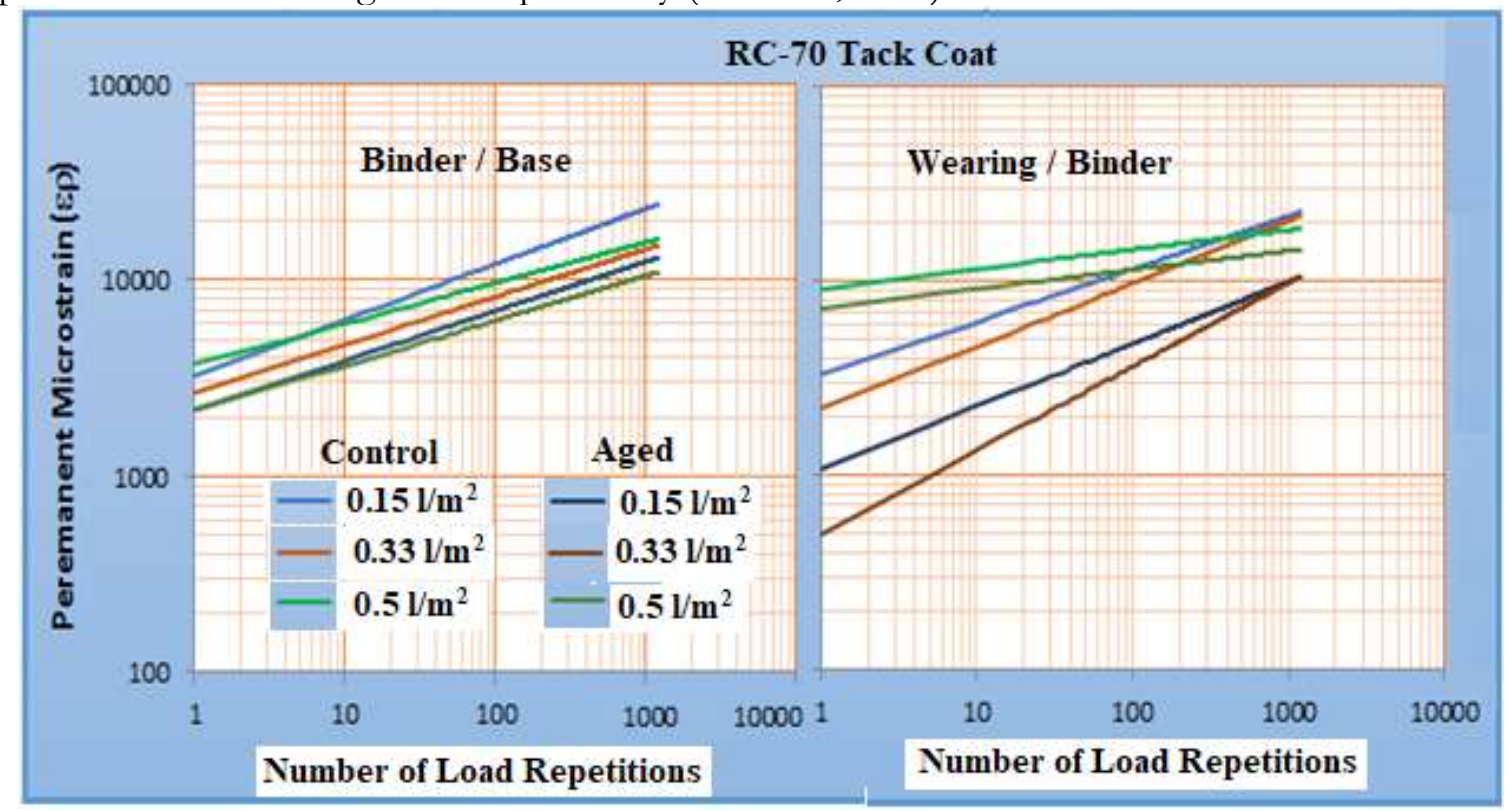

Figure 12. Influence of RC-70 Tack Coat and Ageing on Permanent Microstrain

However, significant variations in the intercept and slope could be observed at the binder-wearing interface. This may be attributed to the smoother surface texture of binder and wearing course layers. Moreover, it can be observed that the long-term ageing of wearingbinder interface was able to reduce the intercept significantly as compared to the (binder-base) interface, while the total permanent deformation was almost the same for aged and control specimens for both interfaces.

Table 6 demonstrates the permanent deformation parameters at interface bond with RC-70 tack coat. It can be observed that the long-term ageing process of the interface exhibit stiffening of asphalt binder and reduction in the total microstrain by (43.6, 25.6, and 29.5) \% for binder-base course interface, while the reduction in the total microstrain by $(50,51.3$, and $30.2) \%$ for wearing-binder course interface for the application rate of $(0.15,0.33,0.5) 1 / \mathrm{m}^{2}$ respectively.

Table 6. Permanent Deformation Parameters at interface bond with RC-70 tack coat

\begin{tabular}{|c|c|c|c|c|c|c|}
\hline $\begin{array}{l}\text { Tack } \\
\text { Coat } \\
\text { Type }\end{array}$ & Layer & Process & $\begin{array}{c}\text { Application } \\
\text { Rate }\end{array}$ & Intercept & Slope & Microstrain \\
\hline \multirow{6}{*}{ RC-70 } & \multirow{6}{*}{$\begin{array}{c}\text { Binder / } \\
\text { Base }\end{array}$} & \multirow{3}{*}{ Control } & 0.15 & 3287.1 & 0.2822 & 25200 \\
\hline & & & 0.33 & 2674.3 & 0.2453 & 16400 \\
\hline & & & 0.5 & 3742.8 & 0.2064 & 18600 \\
\hline & & \multirow{3}{*}{ Aged } & 0.15 & 2179.1 & 0.2519 & 14200 \\
\hline & & & 0.33 & 2160.2 & 0.2321 & 12200 \\
\hline & & & 0.5 & 2158.3 & 0.2294 & 13100 \\
\hline
\end{tabular}




\begin{tabular}{|l|l|l|c|c|c|c|}
\hline \multirow{3}{*}{$\begin{array}{l}\text { Wearing } \\
\text { J Binder }\end{array}$} & \multirow{3}{*}{ Control } & 0.15 & 3296.0 & 0.2724 & 23000 \\
\cline { 3 - 6 } & & 0.33 & 2194.2 & 0.3243 & 22400 \\
\cline { 3 - 6 } & \multirow{3}{*}{ Aged } & 0.5 & 9216.6 & 0.0996 & 23500 \\
\cline { 3 - 6 } & & 0.15 & 1089.9 & 0.3203 & 11500 \\
\cline { 3 - 6 } & & 0.33 & 498.76 & 0.4318 & 10900 \\
\cline { 3 - 6 } & & 0.5 & 7307.5 & 0.0975 & 16400 \\
\hline
\end{tabular}

\subsection{Impact of CMS Tack Coat and Ageing on Permanent Microstrain under Repeated Shear Stresses}

Figure 13 demonstrates the influence of repeated shear stresses and ageing process on permanent microstrain at the pavement interfaces when CMS tack coat was implemented. It can be noted that the impact of ageing on permanent microstrain is significant for (binderbase) and (wearing-binder) interfaces. The influence of ageing is more pronounced in case of the (wearing-binder). This may be attributed to the fine surface texture of binder and wearing courses. The variation in the slope is not significant among various application rates of tack coat and interfaces. Moreover, it can be observed that the long-term ageing of (wearingbinder) and (binder-base) interfaces was able to reduce the intercept significantly by a range of (40-50) $\%$ as compared to the case before ageing. The total permanent deformation was almost the same for aged and control specimens for both interfaces.

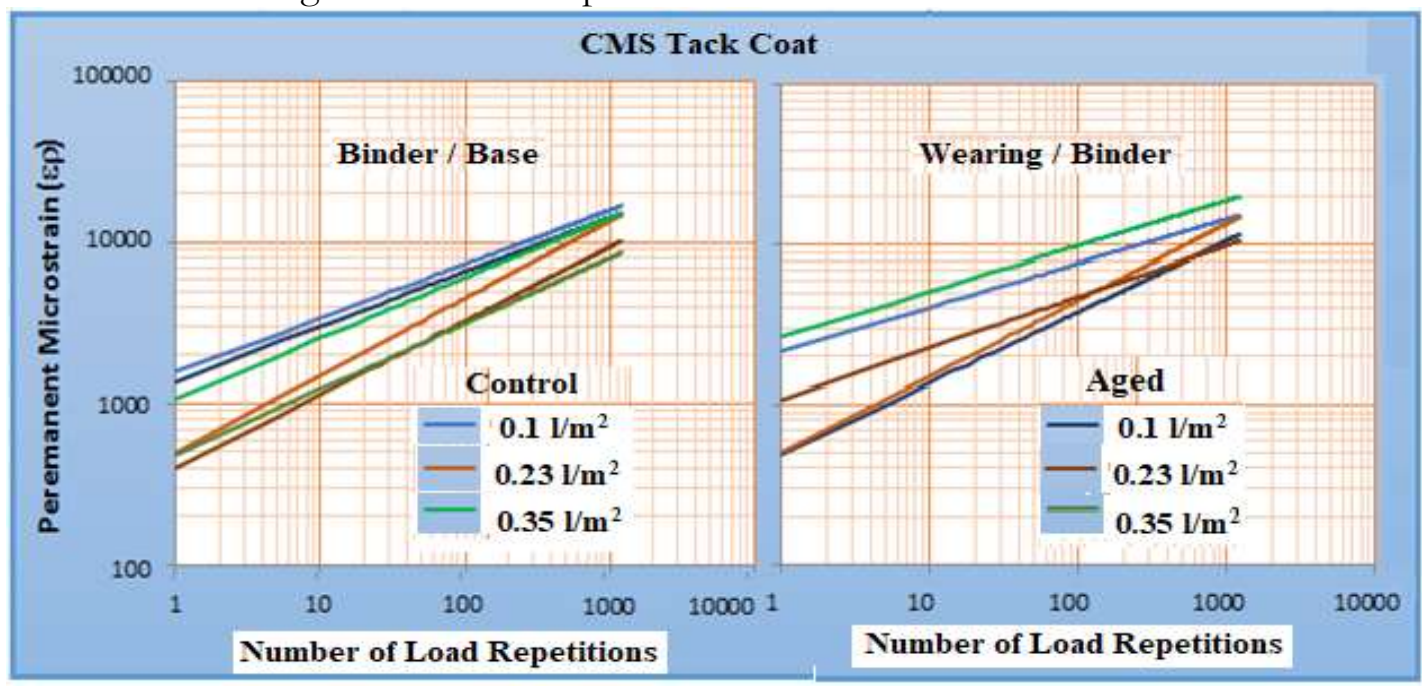

Figure 13. Influence of CMS Tack Coat and Ageing on Permanent Microstrain

Table 7 demonstrates the permanent deformation parameters at interface bond with CMS tack coat. It can be observed that the long-term ageing process of the interface exhibit stiffening of asphalt binder and reduction in the total microstrain by $(37,35.5$, and 40.3$) \%$ for binder-base course interface.

Table 7. Deformation Parameters at interface bond with CMS tack coat

\begin{tabular}{|c|c|c|c|c|c|c|}
\hline $\begin{array}{c}\text { Tack } \\
\text { Coat } \\
\text { Type }\end{array}$ & Layer & Process & $\begin{array}{c}\text { Application } \\
\text { Rate }\end{array}$ & Intercept & Slope & Microstrain \\
\hline \multirow{3}{*}{ CMS } & \multirow{3}{*}{$\begin{array}{c}\text { Binder } / \\
\text { Base }\end{array}$} & \multirow{2}{*}{ Control } & 0.1 & 3287.1 & 0.3333 & 25200 \\
\cline { 4 - 7 } & & \multirow{2}{*}{ Aged } & 0.23 & 2674.3 & 0.4795 & 16400 \\
\cline { 4 - 7 } & & & 0.35 & 3742.8 & 0.3721 & 18600 \\
\cline { 4 - 7 } & & & 0.1 & 1393.5 & 0.3373 & 15900 \\
\cline { 3 - 6 } & & & 0.35 & 486.39 & 0.4052 & 11100 \\
\hline
\end{tabular}




\begin{tabular}{|c|c|c|c|c|c|c|}
\hline \multirow{3}{*}{ CMS } & \multirow{3}{*}{\begin{tabular}{c}
$*$ \\
\multirow{3}{*}{ Control }
\end{tabular}} & 0.1 & 3296.0 & 0.2756 & 23000 \\
\cline { 3 - 6 } & Wearing & 0.23 & 2194.2 & 0.4793 & 22400 \\
\cline { 3 - 6 } & & 0.35 & 9216.6 & 0.2837 & 23500 \\
\cline { 3 - 6 } & & \multirow{3}{*}{ Aged } & 0.1 & 495.28 & 0.4441 & 12600 \\
\cline { 3 - 6 } & & 0.23 & 1090.4 & 0.3196 & 11400 \\
\cline { 3 - 6 } & & 0.35 & 2532.0 & 0.4011 & 12500 \\
\hline
\end{tabular}

However, the reduction in the total microstrain by $(45.2,49$, and 46.8$) \%$ for wearingbinder course interface for the application rate of $(0.1,0.23,0.35) 1 / \mathrm{m}^{2}$ respectively. Such findings agree well with the work reported by (Karakas, 2018).

\subsection{Effect of Long-Term Aging on Interface Bond Shear Strength}

As demonstrated in Figure 14, long-term ageing process exhibit positive influence on interface bond shear strength. When RC-70 tack coat was implemented, the IBSS increases by $(27.4,8,14.2) \%$ for (binder-base) interface and $(16,18.2,22) \%$ for (wearing-binder) interface at the application rate of $(0.15,0.33,0.5) 1 / \mathrm{m}^{2}$ respectively. On the other hand, When CMS tack coat was implemented, the IBSS increases by $(20,20.8,8.7) \%$ for (binder-base) interface and $(25.3,4,15) \%$ for (wearing-binder) interface at the application rate of $(0.1,0.23,0.35)$ $1 / \mathrm{m}^{2}$ respectively. Similar findings were reported by (Raab and Partl, 2004), and (Zhang, 2017).

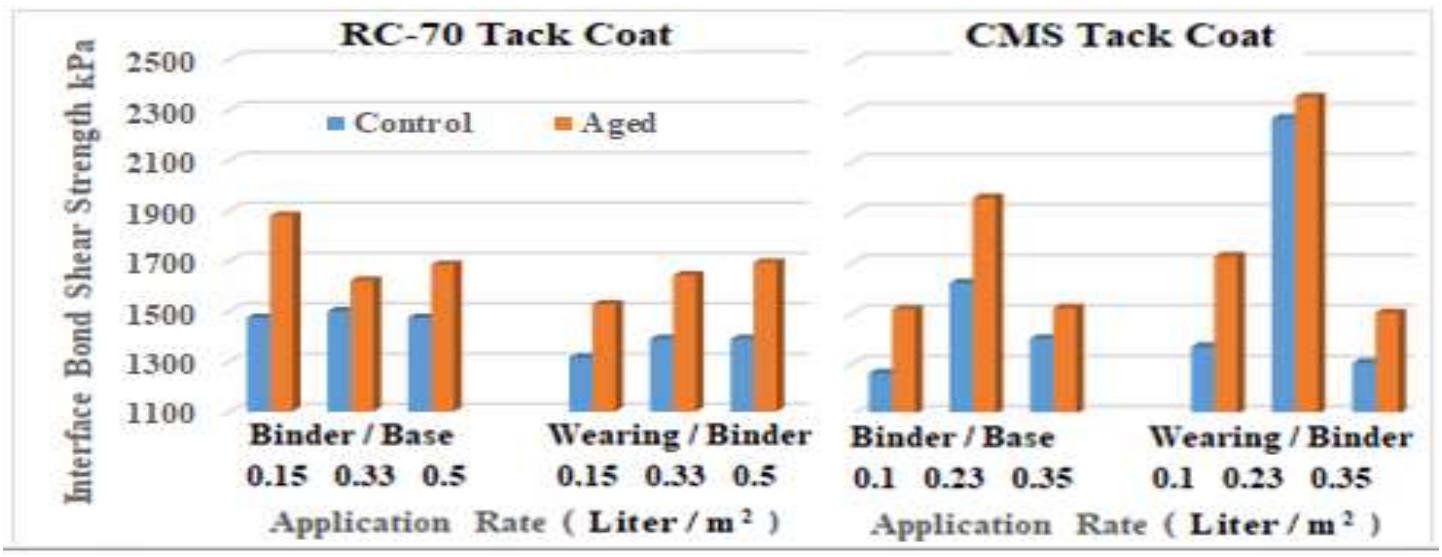

Figure 14. Influence of Ageing on Interface Bond Shear Strength

\section{Conclusion}

Based on the limitations of materials and testing, the following conclusions may be drawn.

1. At interface with RC-70 tack coat, the long-term ageing process exhibit reduction in the total microstrain by $(43.6,25.6$, and 29.5$) \%$ and $(50,51.3$, and 30.2$) \%$ for (binder-base) and (wearing-binder) interfaces for the application rate of $(0.15,0.33,0.5) 1 / \mathrm{m} 2$ respectively.

2. At interface with CMS tack coat, the long-term ageing process exhibit reduction in the total microstrain by $(37,35.5$, and 40.3$) \%$ and $(45.2,49$, and 46.8) $\%$ for (binder-base) and (wearing-binder) interfaces for the application rate of $(0.1,0.23,0.35) 1 / \mathrm{m} 2$ respectively.

3. When RC-70 tack coat was implemented, the IBSS increases by $(27.4,8,14.2) \%$ for (binder-base) interface and $(16,18.2,22) \%$ for (wearing-binder) interface at the application rate of $(0.15,0.33,0.5) 1 / \mathrm{m} 2$ respectively.

4. When CMS tack coat was implemented, the IBSS increases by $(20,20.8,8.7) \%$ for (binderbase) interface and $(25.3,4,15) \%$ for (wearing-binder) interface at the application rate of $(0.1,0.23,0.35) 1 / \mathrm{m} 2$ respectively. 


\section{References}

Muslich, S. (2010). Assessment of Bond between Asphalt Layers. Ph.D. Thesis, University of Nottingham, Nottingham, UK.

Raab C., Grenfell J., Abd El Halim A., Partl M., (2016). Comparison of interlayer bond behavior due to ageing. Proceedings, 8th RILEM International Symposium on Testing and Characterization of Sustainable and Innovative Bituminous Materials, vol. 11, pp. $323-334$.

Karakas A. S. (2018). Aging Effects on Mechanical Characteristics of Multi-Layer Asphalt Structure. Book chapter, Licensee Intech Open, P.22-40. http://dx.doi.org/10.5772/intechopen.75698.

Swarna S. T. (2018). Effect of Interface Bonds on Pavement Performance. PhD Dissertation, Department of Civil Engineering, Memorial University, Newfoundland, A1B 3X5, Canada.

Shahin, M.Y., Kirchner, K., Blackmon, E.W., and Tomita, H. (1986). Effect of Layer Slippage on Performance of Asphalt-Concrete Pavements. Transportation Research Record: Journal of the Transportation Research Board, No. 1095, pp. 79-85, Washington, D.C., Transportation Research Board of the National Academies.

Raab, C.; Partl, M. (2009). Influence of the gap width between the shearing rings on interlayer shear bond testing. In Proceedings of the Second International Conference environmentally friendly Roads, Enviroad, Warsaw, Poland, 15-16 October.

Kulkarni M. B. (2004). Effect of tack and prime coats, and baghouse fines on composite asphalt pavements. PhD Dissertation. North Carolina State University. April.

Raab, C., and Partl M. (2004). Effect of Tack Coats on Interlayer Shear Bond of Pavements. In 8th Conference on Asphalt Pavements for Southern Africa, p. 9.

Khweir, K., and D. Fordyce. (2003). Influence of Layer Bonding on the Prediction of Pavement Life. Proceedings of the Institution of Civil Engineering-Transport, Vol. 156, pp. $73-83$.

Nurmaidah and Pradana Y. (2019). The Effect of the Mixture of Plastic Waste as a Lightweight Concrete Material. Budapest International Research in Exact Sciences (BirEx) Journal. Volume 1, No 2, April, Page: 65-75. DOI : https://doi.org/10.33258/birex.v1i2.227.

ASTM, (2013). Road and Paving Materials. Annual Book of ASTM Standards, Volume 04.03, American Society for Testing and Materials, USA.

SCRB, (2003). Standard Specification for Roads and Bridges. Section R/9, Revised Edition. State Commission of Roads and Bridges, Ministry of Housing and Construction, Republic of Iraq.

AASHTO. (2013). Standard Specification for Transportation Materials and Methods of Sampling and Testing, American Association of State Highway and Transportation Officials, 14th Edition. Part II, Washington, D.C.

EN 12697 - 33 (2007). Bituminous Mixtures - Test Methods for Hot Mix Asphalt - part 33: Specimen prepared by Roller Compactor, European Committee for Standardization.

Mirsayara M., Shia X., and Zollingera D. (2017). Evaluation of interfacial bond strength between Portland cement concrete and asphalt concrete layers using bi-material SCB test specimen. Engineering Solid Mechanics, 293-306. homepage: www.GrowingScience.com/esm.

Zhang W. (2017). Effect of tack coat application on interlayer shear strength of asphalt pavement: A state-of-the-art review based on application in the United States. International Journal of Pavement Research and Technology 10 434-445. (http://creativecommons.org/licenses/by-nc-nd/4.0/). 
Biglari M., Asgharzadeh S., Tehrani S. (2019). Evaluation of factors affecting tack coat bond strength. Canadian Journal of Civil Engineering, Vol. 46, No. 4 : pp. 270-277 https://doi.org/10.1139/cjce-2018-0290.

Sarsam S. I. and Hamdan R. K. (2020).Modeling the Influence of Surface Free Energy on Moisture Damage of Recycled Asphalt Concrete. Budapest International Research in Exact Sciences (BirEx)Journal Volume 2, No 2, April 2020, Page: 168-183. www.bircujournal.com/index.php/birex

Sarsam S. I. and Muayad S. (2014). Influence of Aging Time on Asphalt Pavement Performance. Journal of Engineering, Vol.20 No.12. (P1-12).

Hu et al., Yan K., You L.(2016). Mechanical Response Analysis of Asphalt Concrete Overlay Placed on Asphalt Pavement Considering Cross-Anisotropic Pavement Materials. ASCE Transportation research congress, https://ascelibrary.org/doi/10.1061/9780784481240.035 